\title{
Murramarang Beach
}

\author{
Emma McCulloch
}

University of Technology Sydney, Faculty of Arts and Social Sciences, PO Box 123, Ultimo NSW 2017, Australia.emma.mcculloch@student.uts.edu.au

\section{DOI: $\underline{\text { https://doi.org/10.5130/nesais.v4i1.1518 }}$}

The site I chose to reflect on is Murramarang beach. This is an important place when thinking about Aboriginal political history, as it depicts life prior to colonisation but was also significant during colonisation. Murramarang would have been the carinya ('happy home') to either a single tribe or a meeting place between surrounding tribes, but my connection to this land lies in it being my second place of home.

The landscape is varied and holds spiritual significance through its many features being linked to stories of the Dreamtime, and the vegetated sandbanks protect the Aboriginal Area which the Local Aboriginal Land Council utilise for recreational and educational purposes. The heritage walk that takes you through what used to be the largest midden on the south coast describes the history of the area and how Indigenous communities occupied the land.

What I found to be most interesting is the weaving together of time and interpretations of place. I would often spend extended periods of time at Murramarang during my childhood years and was gifted in being able to see what the land had to provide. As a child, your imagination wanders and the headland becomes a place where you can hide from threats such as your boring parents. The freshwater lake that runs into the sea becomes a fun place to chase fish and the sandbanks make finding kangaroos easy. This perspective has allowed me to imagine what life could have been like thousands of years ago. An image of abundance and harmony can be visualised but as I grew older, I became more aware of how Murramarang fitted into the story of colonisation.

Evidence of colonisation is clear: there are mostly 'white' inhabitants of the beach today and as Captain Cook made his voyage in 1770, he famously named the mountain that was traditionally known as 'Didthil' Pigeon House Mountain. Murramarang also received a specific mention in Cook's diary, with him noting that on the 22nd of April he made the first sighting of Indigenous Australians both on the beach and in wooden canoes. What makes me question the effects of colonisation the most was the massacre on Murramarang which killed large numbers of local Aboriginal people (Australian National University 2015). The massacre occurred due to cultural misunderstandings and is important when questioning if colonisation should be historically framed as an 'invasion' rather than a 'settlement'. 
Overall, it is important to see Murramarang not only as a tourist stop, but also as a place that holds stories of Australia's history. The Indigenous culture is protected and the narratives of colonisation and post-colonisation remain.

\section{References}

Australian National University 2015, They Came to Murramarang, ANU Press, Canberra.

(c) (1) 2018 by the author(s). This article is distributed under the terms and conditions of the Creative Commons Attribution license (http://creativecommons.org/licenses/by-nd/4.0/). 